\title{
APLICAÇÃo DE ANÁLISE MULTICRITERIAL PARA DETERMINAÇÃo DE ÁREAS PRIORITÁRIAS À RECOMPOSIÇÃO FLORESTAL
}

\section{FÁBIO ÁVILA NOSSACK ${ }^{1}$; CÉLIA REGINA LOPES ZIMBACK ${ }^{1}$; RAMON FELIPE BICUDO DA SILVA ${ }^{2}$ E ANDERSON ANTÔNIO DA CONCEIÇÃO SARTORI ${ }^{1}$}

\author{
${ }^{1}$ Departamento de Ciência do Solo, Faculdade de Ciências Agronômicas, Universidade Estadual Paulista, Botucatu, \\ SP, fnossack@gmail.com \\ ${ }^{2}$ Núcleo de Estudos e Pesquisas Ambientais - Universidade Estadual de Campinas, Campinas, SP, \\ ramonbicudo@gmail.com
}

\section{RESUMO}

Utilizando Sistemas de Informação Geográficas (SIG's), dada sua capacidade de análise de dados de natureza espacial, foi confeccionado um banco de dados espacial atualizado da sub-bacia do córrego do Descalvado, município de Botucatu, SP, possibilitando uma avaliação e diagnostico da área quanto à ocupação do território e os processos de degradação que nela ocorrem. Através do SIG foram definidas áreas prioritárias à recomposição florestal por meio da Avaliação Multicritérios, utilizando o método da Média Ponderada Ordenada, que permite que o tomador de decisão decida pela recuperação de uma área, frente a uma limitação de recursos, entre um dos cenários propostos ou o faça por etapas. Conclui-se que há presença de processos erosivos acelerados nas cabeceiras de nascentes dos corpos d'água; há fragmentação da vegetação nativa, principalmente nas áreas de encosta e pequena presença de vegetação nativa nas zonas ripárias. A aplicação da Análise Multicriterial pelo método da Média Ponderada Ordenada foi importante, pois discriminou e sistematizou os cenários de prioridade para a recomposição florestal.

Palavras chave: Média Ponderada Ordenada; Avaliação Multicritérios; Tomada de Decisão; Recuperação Ambiental.

NOSSACK, F.A.; ZIMBACK, C.R.L.; SILVA, R.F.B.; SARTORI, A.A.C. APPLICATION OF MULTICRITERIA ANALYSIS TO DEFINE PRIORITY AREAS FOR FOREST RECOVERY

\section{ABSTRACT}

Using the Geographic Information System (GIS) and taking into account its capability to analyze spatial data, a database of updated spatial data from the sub-basin of the Descalvado stream, Botucatu, SP, was developed to provide an evaluation and diagnosis of the area concerning land use and the degradation processes therein. Through GIS, priority areas for forest recovery were defined by Multicriteria Evaluation and using the Ordered Weighted Average method. The latter allows the decision maker to define the area to be recovered, facing 
limitation of resources, among one of the proposed scenarios, or do it in stages. The study showed that there are accelerated erosion processes in the headwaters of the springs of water bodies; there is also fragmentation of native vegetation, especially in hillside areas, and little presence of native vegetation in riparian areas. The application of the multicriteria analysis using the Ordered Weighted Average was important as it systematized and discriminated scenarios of priority for forest recovery.

Keywords: Ordered Weighted Average, multicriteria evaluation, decision making, environmental recovery.

\section{INTRODUÇÃO}

A busca por novas tecnologias para o estudo e monitoramento do ambiente representa um campo promissor para o desenvolvimento da ciência. As mudanças no uso e cobertura da terra são responsáveis pelas maiores alterações nos ambientes, com consequências para a conservação dos recursos naturais e para a qualidade de vida humana (Moran e Ostrom, 2009; Foley et al., 2005; Foster et al., 1998). Para compreendê-las, o sensoriamento remoto demonstrou significativas contribuições (Lasanta e Vicente-Serrano, 2012; Du et al., 2012; Moran e Ostrom, 2009; Lu et al., 2008), tornando-se fronteira da ciência no século XXI. Com o avanço da ciência, técnicas modernas de obtenção de imagens, associadas aos SIGs, facilitam a obtenção de uma grande quantidade de dados, segundo Vettorazzi (2006), difíceis de serem obtidos sem a sua utilização.

Os recursos hídricos no Brasil e em diversas regiões no mundo são constantemente comprometidos por atividades agrícolas, quando realizadas sem manejo adequado do solo, uso excessivo de fertilizantes e defensivos (Ashok et al., 2007), além do desmatamento e a expansão urbana (Benito et al., 2003). Os cursos d'água frequentemente transportam solo, muitas vezes provenientes de áreas agrícolas adubadas ou corrigidas a altos custos financeiros, contaminando águas superficiais e subterrâneas, comprometendo seu uso para o abastecimento público e na irrigação (Assad et al., 1998).

A supressão de áreas florestais ou a substituição por outras coberturas contribuem para os processos de geração, transporte e deposição de sedimentos nos canais de drenagem (Mohammad e Adam, 2010; Ashok et al., 2007). As florestas de encosta protegem a superfície do solo contra o início do processo erosivo, promovem a infiltração da água no solo e funcionam como barreiras ao transporte dos sedimentos. A zona de entorno das nascentes tem importante função de proteção contra a compactação do solo e o assoreamento, provocados por práticas agrícolas inadequadas. Ao lado dos canais de drenagem, as florestas ripárias ou ciliares, com largura e estrutura adequadas, podem filtrar sedimentos, material orgânico, elementos químicos e compostos associados, promovendo sua deposição no solo antes de atingirem os cursos d'água (Zhang et al., 2014). As matas ciliares protegem diretamente os canais contra a erosão de suas margens e contribuírem para aumentar a capacidade de armazenamento de água na bacia (Vettorazzi, 2006).

Regras para a tomada de decisão são estruturadas no contexto de um objetivo específico. A natureza deste objetivo e como ele é visto pelos tomadores de decisão (isto é, seus motivos) servirão como uma força-guia no desenvolvimento de uma regra de decisão específica. Um 
objetivo é, então, uma perspectiva que serve para guiar a estruturação de regras de decisão. O processo de, efetivamente, aplicar-se a regra de decisão é chamado de avaliação (Vettorazzi, 2006).

A Análise Multicriterial pelo método da Média Ponderada Ordenada (MPO) é uma classe de operadores multicritérios (Yager, 1988). Ela envolve dois conjuntos de pesos: pesos de importância do critério (ou pesos de fatores) e pesos de ordenação. Um peso de importância é assinalado para cada critério (atributo) para todos os locais da área de estudo, para indicar sua importância relativa (de acordo com as preferências do tomador de decisão) em um conjunto de critérios sob consideração (Vettorazzi, 2006).

Os pesos de ordenação estão associados com os valores dos critérios em uma base local-alocal (objeto-a-objeto). Eles são assinalados a um atributo de local, com valores em ordem decrescente, sem assinalar de que atributo o valor é proveniente. Os pesos de ordenação são essenciais aos procedimentos de combinação (agregação) no método da MPO. O parâmetro é também associado com uma medida de compensação (trade-off), indicando o grau de compensação entre critérios. Os parâmetros associados com as operações MPO servem como um mecanismo para guiar a análise de adequação do uso da terra com base em um SIG. A lógica "OU" (o quanto um parâmetro se sobrepõe a outro em grau de importância ou relevância) permite a interpretação dos resultados da MPO no contexto da teoria comportamental da tomada de decisão. As operações MPO tornam possível o desenvolvimento de uma variedade de estratégias de uso da terra, variando do pessimismo extremo (a estratégia do tipo "mínimo", baseada na combinação pela lógica "E"), passando pela estratégia intermediária (neutra) em termos de risco (correspondendo à Combinação Linear Ponderada (CLP) convencional), até a estratégia extremamente otimista (a estratégia do tipo "máximo", baseada na combinação pela lógica "OU”). Desse modo, a MPO pode ser considerada como uma extensão e uma generalização dos procedimentos convencionais de combinação em um SIG. (Vettorazzi, 2006).

Ainda para Vettorazzi, (2006), estratégias para avaliar e decidir sobre a alocação de áreas prioritárias para um determinado fim são importantes no gerenciamento de recursos financeiros. Com o emprego do SIG há a oportunidade para um processo de avaliação de terras explicitamente racional. Entretanto, há necessidade de um constante desenvolvimento de procedimentos e instrumentos para a aplicação de regras de decisão e modelagem preditiva, para que esse potencial do SIG seja efetivamente aproveitado.

Os objetivos deste trabalho foram: analisar o uso e cobertura da terra, os processos de degradação ambiental associados a estes usos e definir, através de avaliação multicriterial pelo método da Média Ponderada Ordenada, áreas prioritárias à recomposição florestal visando a conservação dos recursos hídricos, na sub-bacia do Córrego do Descalvado.

\section{MATERIAL E MÉTODOS}

O presente trabalho teve como área de abrangência a Bacia do Córrego do Descalvado, que possui parte de sua área inserida dentro do perímetro da Área de Proteção Ambiental (APA) Corumbataí, Botucatu, Tejupá. Esta é, de acordo com Silva et al. (2011), importante área de recarga do Aquífero Guarani. A Sub-bacia está situada entre os paralelos $22^{\circ} 57^{\prime} 39^{\prime \prime}$ e $22^{\circ} 39^{\prime}$ $36^{\prime \prime}$ de latitude Sul, e entre os meridianos $48^{\circ} 17^{\prime} 34^{\prime \prime}$ e $48^{\circ} 29^{\prime} 36^{\prime \prime}$ de longitude Oeste de Greenwich. 
A área estudada distribui-se pelas três feições geomorfológicas da Cuesta, sendo que as cotas abaixo de 610 metros são definidas como Depressão Periférica, de 610 metros a 810 metros correspondem ao Front da Cuesta e acima de 810 metros tem-se o reverso da Cuesta, apresentando $12,90 \%$ de sua área localizada sobre o Reverso da Cuesta, 32,25 \% no Front e 54,85 \% na Depressão Periférica. (JIM, 2006)

Segundo Piroli (2002), os tipos de solo que caracterizam a bacia são os Gleissolos Háplicos $\mathrm{Tb}$, os Latossolos Vermelho-Amarelos Distróficos, os Latossolos Vermelhos Distróficos, os Neossolos Litólicos Eutróficos, os Neossolos Quartzarênicos Órticos e os Neossolos Vermelhos Distroférricos.

Para a criação dos bancos de dados e vetorizações das curvas de nível, da rede de drenagem e limite da área de estudo, foram utilizadas as cartas planialtimétricas do Instituto Geográfico e Cartográfico, em escala 1:10.000, com equidistância vertical entre as curvas de nível de 5 metros. As informações foram importadas para o SIG, onde foi gerado o modelo digital de elevação da sub-bacia e, posteriormente, o mapa de declividade. Os intervalos considerados para as classes de declividade, em porcentagem, foram: 0 a 3\%; 3 a 6\%; 6 a $12 \%$; 12 a 20\%; 20 a 40\% e acima de 40\% correspondendo, respectivamente, às classes de relevo: plano, suave ondulado, ondulado, forte ondulado, montanhoso e escarpado segundo Lepsch et al. (1991).

O mapeamento do uso e cobertura da terra foi elaborado utilizando-se uma imagem do satélite SPOT, do ano 2010, de resolução espacial de 10 metros. Este mapa foi produzido pelo processamento digital da imagem orbital. Foi feita a correção geométrica utilizando o modelo de transformação polinomial de primeiro grau e o método de interpolação pelo vizinho mais próximo. Nesta correção houve a identificação e registro das coordenadas de pontos, denominados controle, que foram comuns entre as ortofotos aéreas existentes no banco de dados do Grupo de Estudo e Pesquisas Agrárias Georreferenciadas e a imagem orbital que, por sua vez, representou as coordenadas reais. As informações adquiridas foram organizadas no Plano de Informação (PI) Uso e Cobertura da terra.

Os PIs gerados a partir de bases cartográficas georreferenciadas foram: rede de drenagem, curvas de nível e limite, extraídos à partir da vetorização das cartas topográficas do Instituto Geográfico e Cartográfico (IGC), no programa ArcGis. O plano de informação cobertura vegetal, foi extraído do mapa de uso e cobertura da terra. Esses fragmentos foram individualizados, isto é, passaram a receber identificadores únicos.

Os fatores foram gerados a partir do módulo de suporte à decisão do programa Idrisi Selva. Neste módulo, primeiramente, definiu-se o objetivo da análise, neste caso Conservação dos Recursos Hídricos. Os fatores gerados apresentaram uma escala contínua, que variou de 0 (zero) a 255 (duzentos e cinquenta e cinco), totalizando 256 valores, sendo o zero o valor de menor importância e o 255 o de maior importância. Após isto, selecionou-se o arquivo das restrições, ou seja, as áreas omitidas pela análise. Em sequência, foram gerados os fatores que integram a análise, cada um com um peso, compondo, segundo os critérios, as áreas prioritárias para a conquista do objetivo.

$\mathrm{Na}$ definição dos critérios e, posteriormente, dos pesos de fatores, empregou-se a Técnica Participatória proposta por Eastman (2001), Malczewski (1999), Chen et al. (2001), Valente (2005) e Sartori et al. (2012), que se constitui na reunião e consulta a especialistas das diferentes áreas de interesse do trabalho. Para aplicação dessa técnica, foi feita uma reunião no Grupo de Estudos e Pesquisas Agrárias Georreferenciadas (GEPAG) da Faculdade de Ciências 
Agronômica FCA/UNESP, que conta com vários integrantes de diversas formações e outros pesquisadores de diferentes áreas do conhecimento. Dessa forma, todos os especialistas contribuíram com o projeto, sugerindo fatores (características/atributos da paisagem) e explicando o motivo dessas escolhas, que foram importantes para os objetivos do trabalho.

Os pesos de compensação, que expressam a ordem de importância dos fatores no processo de tomada de decisão foram determinados utilizando o Método da Comparação Pareada, proposto por Saaty (1977) no contexto do Processo Hierárquico Analítico. Esse método baseia-se na elaboração de uma matriz de comparação pareada entre os fatores, de acordo com a importância relativa entre pares de fatores (Eastman, 2001).

Os critérios utilizados foram a proximidade quanto à localização das nascentes e córregos, proximidade quanto aos processos erosivos, proximidade dos fragmentos florestais existentes e as áreas de maior declividade do terreno. Estes fatores são fundamentais para a conservação dos recursos hídricos na sub-bacia hidrográfica. Algumas áreas tiveram que ser descartadas da análise multicriterial, pois já havia ocupação antrópica consolidada ou cobertura florestal. Estas áreas foram restringidas da análise para alocação de projetos de recomposição florestal e assim denominadas "Restrições".

\section{RESULTADOS E DISCUSSÃO}

Os fatores distância das nascentes, distância da rede de drenagem, distância dos processos erosivos, distância dos fragmentos de floresta nativa e áreas com relevo acentuado; gerados no módulo de suporte de decisão do programa Idrisi Selva, bem como as áreas de restrição da análise multicriterial são discriminados na Figura 1. 
Figura 1. Fatores: (A) proximidade das nascentes; (B) proximidade da rede de drenagem; (C) proximidade dos processos erosivos; (D) áreas mais declivosas; (E) proximidade de fragmentos.

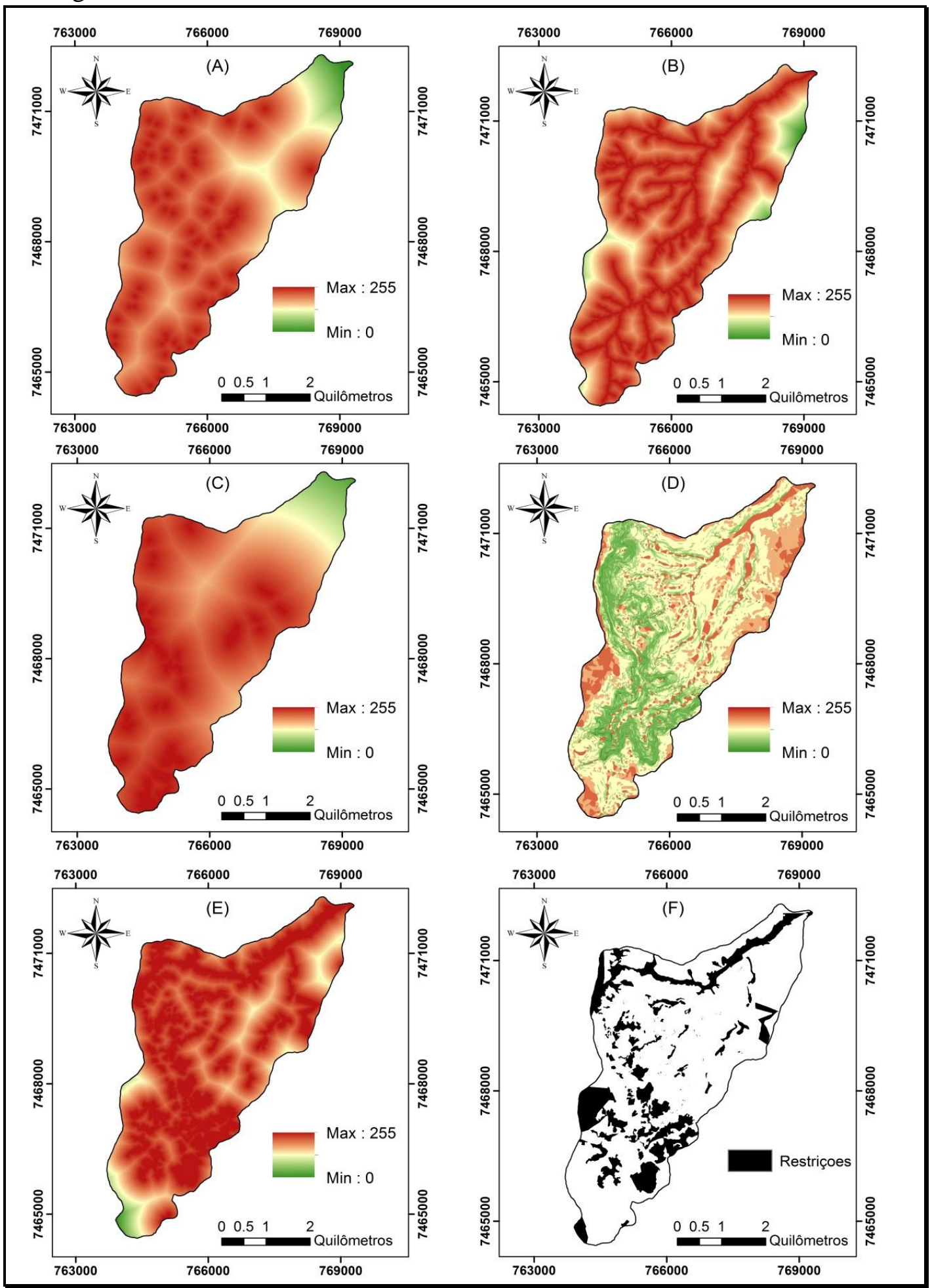

Fonte: acervo pessoal. 
Segundo Eastman (2012), a técnica da Média Ponderada Ordenada, assim como a Combinação Linear Ponderada, é melhor utilizada com fatores que foram normalizados para uma escala contínua de adequação e ponderados de acordo com a sua relativa importância (Matriz de Comparação Pareada). Portanto, até a geração da matriz de pesos, os procedimentos da CLP e MPO são idênticos. No entanto, no caso da MPO, um segundo conjunto de pesos (Pesos de Ordenação) também foram aplicados aos fatores, o que permitiu controlar o nível global de troca entre os fatores, bem como o nível de risco na determinação de adequação.

Definido o método de análise multicriterial, a partir de características relevantes à conservação da água e manutenção do ciclo hidrológico, a seleção de critérios (fatores e restrições) representou parte importante e fundamental na elaboração do mapa final de prioridades.

\subsection{Definição dos Pesos dos Fatores}

Segundo Eastman (2012), uma das vantagens dos métodos da CLP e MPO é a capacidade para dar diferentes pesos relativos a cada um dos elementos no processo de agregação. Fatores de pesos são atribuídos a cada fator, indicando uma importância relativa de todos os outros fatores e eles controlam como fatores compensam um ao outro. Nestes casos, fatores com alta aptidão em um determinado local podem compensar outros fatores com baixa adequação no mesmo local. $\mathrm{O}$ grau em que um fator pode compensar o outro é determinado por seu fator de peso ou de troca.

Os pesos e a prioridade dos respectivos fatores estão representados na matriz de comparação pareada entre os fatores (Tabela 1). O fator de maior peso foi nascentes $(0,4924)$, seguido de rede de drenagem $(0,2014)$, erosões $(0,1263)$, declividade $(0,1018)$ e fragmentos (0,0781). Deve-se ressaltar que o ranqueamento e definição pesos dos fatores foram definidos com aplicação da Técnica Participatória - Análise Hierárquica Analítica, onde especialistas das diferentes áreas de interesse, pertinentes ao tema ou ao processo de tomada de decisão, expõem suas opiniões técnicas sobre a escolha e hierarquização dos fatores para compor a analise final. Essa ponderação teve influência direta na definição das áreas prioritárias à restauração florestal a serem geradas pela análise.

A taxa de consistência (TC) obtida para a matriz foi de 0,09 (menor que 0,10 ), que indica que os valores de comparação entre os fatores foram gerados aleatoriamente, portanto não houve a necessidade de reorganização da matriz. Segundo Eastman (2012), a relação indica qualquer inconsistência que pode ter sido feita durante o processo de comparação par a par. O módulo permite ajustes repetidos para as comparações entre pares e relata os novos pesos e proporções de consistência para cada iteração. Esta taxa é gerada automaticamente pelo módulo de suporte à decisão do programa Idrisi Selva e dá inconsistência quando a taxa fica superior a 0,10 , devendo ter os pesos reajustados até encontrar uma taxa consistente. 
Tabela 1. Matriz de comparação pareada entre os fatores definidos para a Avaliação Multicriterial, apresentando a interação entre os fatores definidos para o estudo, através da Média Ponderada Ordenada.

\begin{tabular}{|c|c|c|c|c|c|c|}
\hline Fatores & Fragmentos Declividade & Erosões & Rede de Drenagem & Nascentes & Pesos \\
\hline Fragmentos & 1 & - & - & - & - & 0,0781 \\
\hline Declividade & 2 & 1 & - & - & - & 0,1018 \\
\hline Erosões & 2 & 2 & 1 & - & - & 0,1263 \\
\hline Rede de Drenagem & 3 & 3 & 2 & 1 & - & 0,2014 \\
\hline Nascentes & 3 & 3 & 5 & 5 & 1 & 0,4924 \\
\hline Taxa de Consistência (TC) & 0,09 & & & & 1,000 \\
\hline
\end{tabular}

Fonte: acervo pessoal

Os fatores de maior preocupação para os pesquisadores têm a si atribuídos a maior parte dos pesos. Os pesos dos dois fatores, distância de Nascentes e de Rede de Drenagem, somam 0.6938 , enquanto os pesos dos outros fatores somam 0,3062 . Isto ocorre pois os dois fatores de maior peso são fortes determinantes da adequação do mapa final.

\subsection{Mapas de Áreas Prioritárias}

Mais importante do que dizer qual mapa melhor representa o cenário atual para a seleção de áreas prioritárias, é o fato de o resultado poder ser manipulado de forma a separar as etapas de recomposição florestal nas áreas em questão, adaptando-se ao momento e disponibilidade financeira para execução da recuperação ambiental. Pode-se interpretar os conceitos de risco, por exemplo, como etapas de adequação, visando atingir o objetivo proposto. Na Tabela 2 estão os pesos de ordenação para o método da Média Ponderada Ordenada, acompanhados do risco de decisão a eles atribuídos. É evidenciada, nos Mapas de Áreas Prioritárias, a relação dos riscos com as etapas de adequação.

Para Eastman (2012), o controle sobre o risco e troca é possível através de um conjunto de pesos de ordenação para as diferentes posições no ranqueamento de fatores em cada local (pixel). Os pesos da ordem, primeiramente, modificam o grau em que os fatores de pesos (obtidos na matriz) terão influência no procedimento de agregação, assim eles vão governar o nível global de troca. Os resultados são classificados de baixo para alta aptidão para cada local. $O$ fator com a menor pontuação nesta adequação é dada a primeira ordem de peso, o fator com a seguinte pontuação mais baixa é dada a segunda ordem de peso, e assim por diante. Isto tem o efeito de ponderação dos fatores com base em sua posição do mínimo ao máximo valor para cada local. A inclinação em relação à direção mínimo - máximo dos pesos de ordenação controla o nível de risco na avaliação. Além disso, o grau em que a ordem dos pesos é distribuída em todas as posições controla o nível de troca global, isto é, o grau no qual o fator tem influência. 
Tabela 2. Pesos de ordenação para os fatores utilizados na Avaliação Multicritérios, pelo método da Média Ponderada Ordenada, mostrando o grau em que a ordem dos pesos é distribuída para cada cenário, onde cada cenário poderá ser um estágio no processo de recuperação florestal.

\begin{tabular}{|c|c|c|c|c|c|}
\hline \multirow{2}{*}{ Cenário } & \multicolumn{5}{|c|}{ Pesos de Ordenação } \\
\cline { 2 - 6 } & Fragmentos & Declividade & Erosões & R. de Drenagem & Nascentes \\
\hline Risco Baixo & 1 & 0 & 0 & 0 & 0 \\
\hline Risco médio/baixo & 0,4300 & 0,2639 & 0,1900 & 0,0941 & 0,0220 \\
\hline Risco médio (CLP) & 0,20 & 0,20 & 0,20 & 0,20 & 0,20 \\
\hline Risco médio/alto & 0,0220 & 0,0941 & 0,1900 & 0,2639 & 0,4300 \\
\hline Risco Alto & 0 & 0 & 0 & 0 & 1 \\
\hline
\end{tabular}

Fonte: acervo pessoal

Nesta tabela, os pesos são distribuídos ou dispersos uniformemente entre todos os fatores, independentemente da sua posição de classificação de ordem do mínimo ao máximo para uma determinada localização. Para o procedimento da CLP, seu resultado será exatamente no meio, em termos de risco, porque para todas as posições de ordenação é dado o mesmo peso, sem posição de classificação de ordem haverá troca completa entre os fatores, permitindo que os pesos dos fatores sejam totalmente utilizados.

Esta forma de compor os cenários permite fluidez aos tomadores de decisão, que frente aos conflitos políticos e/ou financeiros tem de tomar à decisão de quanto investir ou quais áreas deverão ser definidas para a conservação. Tais questões afetam todos os que vivem ou retiram seu sustento a partir dor recursos da sub-bacia, porém, como esta já é uma área prevista para conservação, quando delimitada a Área de Preservação Ambiental, há de se esperar uma política pública de adequação destas áreas, restando apenas resolver o problema de distribuição de recursos e definição da metodologia de recomposição florestal das áreas e readequação econômica dos que lá vivem.

Pode-se, então, enxergar os riscos baixos como estratégia mais pessimista ou de ação mínima para a conquista do objetivo proposto e os riscos altos como estratégia mais otimista ou de ação máxima, visto que mais áreas seriam restauradas e conservadas neste do que naquele. A Figura 2 demonstra as etapas de adequação ambiental visando a conservação dos recursos hídricos na sub-bacia, indo do cenário mais pessimista ao mais otimista com relação à quantidade de área definida para a conservação.

Figura 2. (A) Mapa de Áreas Prioritárias - Risco baixo ou de esforço mínimo de recomposição florestal visando à conservação dos recursos hídricos para a sub-bacia do Córrego do Descalvado; (B) Mapa de Áreas Prioritárias - Risco Médio/Baixo. Segunda etapa de adequação visando à conservação dos recursos hídricos para a sub-bacia do Córrego do Descalvado; (C). Mapa de Áreas Prioritárias - Risco Médio. Terceira etapa de adequação visando à conservação dos recursos hídricos para a sub-bacia do Córrego do Descalvado; (D) Mapa de Áreas Prioritárias - Risco Médio/Alto. Quarta etapa de adequação visando à conservação dos recursos hídricos para a sub-bacia do Córrego Descalvado; (E). Mapa de Áreas Prioritárias - Risco Alto. Última etapa de adequação 
visando à conservação dos recursos hídricos para a sub-bacia do Córrego do Descalvado.

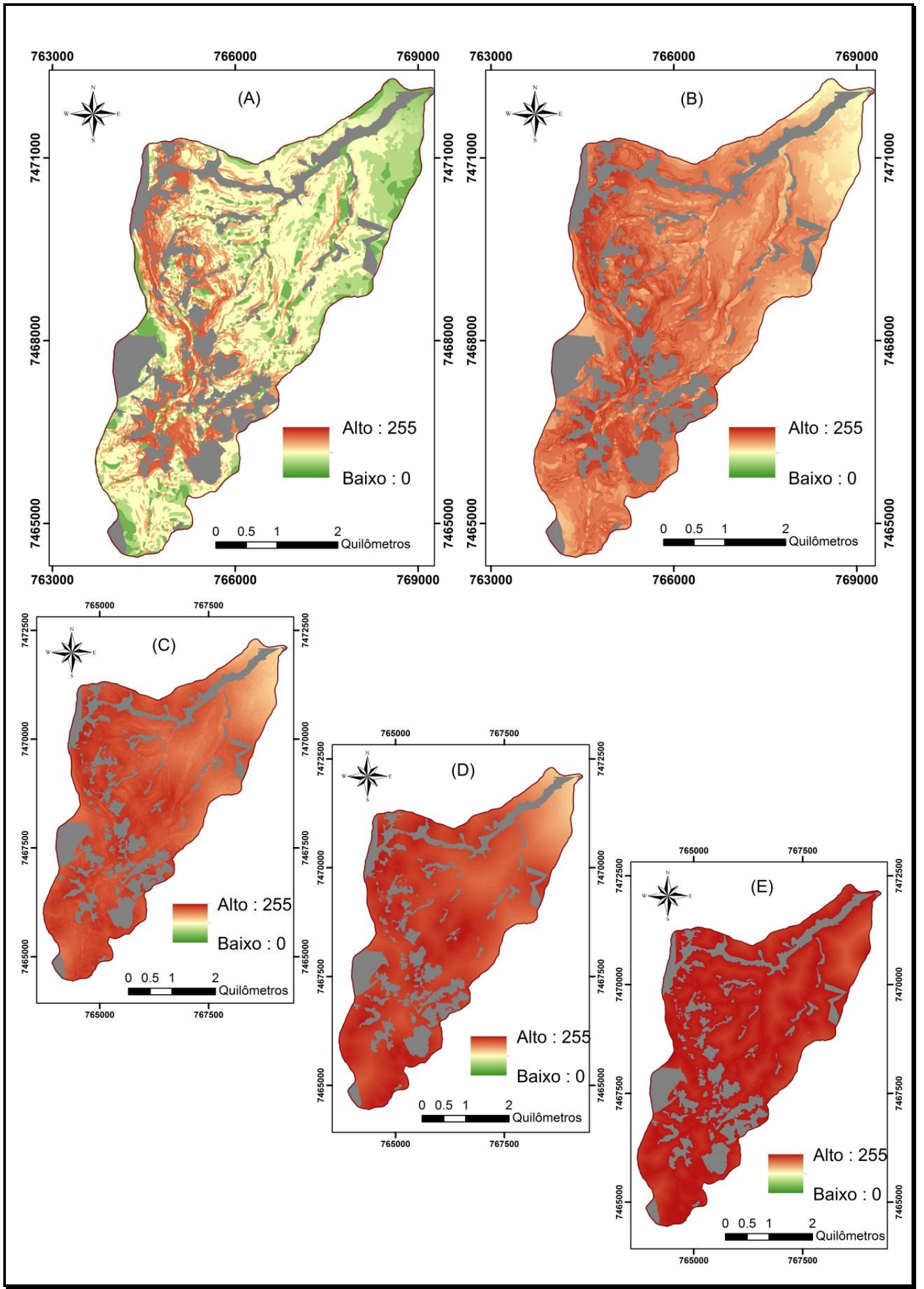

Fonte: acervo pessoal 
O diagnóstico da área mostrou que há ocorrência de degradação ambiental em grande parte da sub-bacia do Descalvado, com ocorrência de erosões em avançado estágio e fragmentação da vegetação nativa. Os mapas de áreas prioritárias, apresentados neste trabalho, sistematiza a recuperação das áreas sem vegetação nativa. Os cenários apresentados servem como base para dimensionar projetos de plantio para recuperação florestal, podendo começar com o mais pessimista, onde se gasta menor quantidade de recursos, mas, ao menos, se garante a manutenção das vegetações nas áreas mais sensíveis, permitindo maior conservação dos recursos hídricos.

A recuperação das áreas propostas neste trabalho beneficia a conexão dos fragmentos florestais existentes, segundo Lathrop et al. (1998) e Geneletti (2004), favorecendo ações de conservação e preservação florestal, haverá contribuição para a reestruturação dos componentes básicos da estrutura de uma paisagem e visa manter a integridade de sua cobertura florestal natural.

A área de estudo escolhida é crítica para a conservação da água, pois pertence à Área de Preservação Ambiental (APA) Corumbataí - Tejupá - Botucatu, que, por definição, é uma área que necessita de conservação. Por esta razão todo seu uso deve estar comprometido com a conservação dos recursos naturais. Empreendimentos contrários a este princípio devem ser realocados para áreas que os suportem sem tantos riscos ao ambiente.

Os problemas que envolvem a determinação de áreas prioritárias à restauração/recomposição florestal convergem à conjuntura política, social e ambiental. Primeiro social, pois, culturalmente, é tida como perda de território a conservação das florestas pelos proprietários de terra. Não há o entendimento do benefício que a conservação traz à sociedade e há falta de incentivo econômico para esta ação (ecoturismo, vantagens financeiras para praticas sustentáveis, extrativismo, manejo florestal, etc.). Depois há o problema político, em geral o que se percebe é a falta de comprometimento com a recuperação do ambiente degradado ou de políticas públicas eficazes de mitigação do impacto que as atividades econômicas poluidoras geram nos ecossistemas. Por último a ambiental, recursos naturais passam por descargas cada vez maiores de agentes poluidores e são reféns de práticas agrícolas intensas e não conservacionistas.

Seguindo o panorama atual de uso e conservação do solo, é apenas uma questão de tempo até os recursos chegarem a níveis críticos e a solução dos problemas se tornarem uma questão de necessidade básica. Portanto, metodologias de recomposição devem ser estudadas e otimizadas, pois, quando a recuperação ambiental se tornar uma necessidade real da sociedade haverá um caráter de urgência na sua execução.

\section{CONCLUSÕES}

A Avaliação Multicriterial utilizando o método da Média Ponderada Ordenada foi, segundo a experiência nesta pesquisa, uma ferramenta de suporte à decisão adequada, sendo este método o mais recomendado para a definição de áreas prioritárias à recomposição florestal, principalmente frente a argumentos antagônicos das diferentes classes da sociedade e a falta de recursos financeiros e humanos, pois demonstra cenários que podem se adaptar as suas ideias e limitações, visando atingir o objetivo final. 
Conclui-se que há presença de processos erosivos acelerados nas cabeceiras de nascentes dos corpos d’água; há fragmentação da vegetação nativa, principalmente nas áreas de encosta e pequena presença de vegetação nativa nas zonas ripárias.

A aplicação da Análise Multicriterial - método da Média Ponderada Ordenada foi importante, pois discriminou e sistematizou os cenários de prioridade da recomposição florestal. A metodologia aplicada pode variar de acordo com as características da área, com o interesse e objetivo do estudo.

As informações geoespaciais geradas a partir dos procedimentos metodológicos deste estudo tem alto potencial para favorecer a recuperação florestal e conservação dos recursos hídricos na sub-bacia do córrego do Descalvado.

\section{REFERÊNCIAS}

ASHOK, M.; KAR, S.; SINGH, V. P. Prioritizing structural management by quantifying the effect of land use and land cover on watershed runoff and sediment yield. Water Resources Managenment, Berlin, v. 21, p. 1899-1913, 2007.

ASSAD, E. D. et al. Estruturação de dados geoambientais no contexto de microbacia hidrográfica. In: ASSAD, E. D.; SANO, E. E. Sistema de informações geográficas: aplicações na agricultura. 2. ed. Planaltina: Centro de Pesquisa Agropecuária dos Cerrados/ Embrapa, 1998. cap. 7 , p. 119-137.

BENITO, E.; SANTIAGO, J. L.; DE BLAS, E.; VARELA, M. E. Deforestation of waterrepellent soils in Galicia (NW Spain): effects on surface runoff and erosion under simulated rainfall. Earth Surface Process Land, Vigo, v. 28, p. 145-155, 2003. doi:10.1002/esp.431.

CHEN, K. P.; BLONG, R.; JACOBSON, C. MCE-RISK. Integrating multicriteria evaluation and gis for risk decision-making in natural hazards. Environmental Modeling e Software, Stanford, v. 16, n. 4, p. 387-397, 2001.

DU, P.; XIA, J.; ZHANG, W.; TAN, K.; LIU, Y.; LIU; S. Multiple classifier system for remote sensing image classification: a review. Sensors, Basel, v. 12, n. 4, p. 4764-4792, 2012.

EASTMAN, J. R. Decision support: decision strategy analysis. Idrisi 32 release 2: guide to GIS and image processing. Worcester: Clark Labs, Clark University, 2001. v. 2, 22 p.

EASTMAN, J. R. Idrisi Selva tutorial: manual version 17. Worcester: Clark Labs, Clark University, 2012. v. 1, 354 p.

FOLEY, J. A.; DEFRIES, R.; ASNER, G. P.; BARFORD, C.; BONAN, G.; CARPENTER, S. R.; CHAPIN, F. S.; COE, M. T.; DAILY, C.; GIBBS, H. K.; HELKOWSKI, J. H.; HOLLOWAY, T.; HOWARD, E. A.; KUCHARIK, C. J.; MONFREDA, C.; PATZ, J. A.; PRENTICE, I. C.; RAMANKUTTY, N.; SNYDER, P. K. Global consequences of land use. Science, New York, v. 309, p. 570-574, 2005. 
FOSTER, D. R.; MOTZKIN, G.; SLATER, B. Land-use history as long-term broad-scale disturbance: regional forest dynamics in Central New England. Ecosystems, Petersham. v. 1, p. 96-119, 1998.

GENELETTI, D. Using spatial indicators and value functions to asses ecosystem fragmentation caused by linear infrastructures. International Journal of Applied Earth Observation and Geoinformation. Maryland Heights. v. 5, p.1-15, 2004.

JIM, A. S. Geoprocessamento aplicado no diagnóstico físico-ambiental. 2006. 109 f. Dissertação (Mestrado em Energia na Agricultura)-Faculdade de Ciências Agronômicas, Universidade Estadual Paulista, Botucatu, 2006.

LATHROP, R. G.; BOGNAR, J. A. Applying GIS and landscape ecological principles to evaluate land conservation alternatives. Landscape and Urban Planning. Maryland Heights. v. 41, p. 27-41, 1998.

LASANTA, T.; VICENTE-SERRANO, S. M. Complex land cover change processes in semiarid Mediterranean regions: An approach using Landsat images in northeast Spain. Remote Sensing of Environment. Maryland Heights. n. 124, p. 1- 14, 2012.

LEPSCH, I. F. et al. Manual para levantamento utilitário do meio físico e classificação de terras no sistema de capacidade de uso: 4a aproximação. Campinas: Sociedade Brasileira de Ciência do Solo, 1991. 175 p.

LU, D.; BATISTELLA, M.; MORAN, E. Integration of Landsat TM and SPOT HRG images for vegetation change detection in the Brazilian Amazon. Photogrammetric Engineering and Remote Sensing. Maryland Heights . 74, p. 421-430. 2008.

MALCZEWSKI, J. GIS and multicriteria decision analysis. New York: John Wiley, 1999. 362 p.

MOHAMMAD, A. G.; ADAM, M. A. The impact of vegetative cover type on runoff and soil erosion under different land uses. Catena. Amsterdã. 81:97-103. doi:10.1016/j.catena. 2010

MORAN, E. F.; OSTROM, E. (Org.) Ecossistemas florestais: interação homem-ambiente. São Paulo: Senac/Edusp, 2009. 544 p.

PIROLI, E. L. Geoprocessamento na determinação da capacidade e avaliação do uso da terra no município de Botucatu - SP. 2002. 108 f. Tese (Doutorado em Agronomia/Energia na Agricultura)-Faculdade de Ciências Agronômicas, Universidade Estadual Paulista, Botucatu, 2002.

SAATY, L. L. A scaling method for priorities in hierarchical structures. Journal of Mathematical Psychology. San Diego. v. 15, p. 234-281, 1977. 
SARTORI, A. A. C. SILVA, R. F. B. da; Zimback, C. R. L. Combinação linear ponderada na definição de áreas prioritárias à conectividade entre fragmentos florestais em ambiente SIG.

Revista Árvore. v. 36, p. 1079-1090, 2012.

SILVA, R. F. B.; NOSSACK, F. A.; SARTORI, A. A. C.; ZIMBACK, C.R.L.; MORAES, P. I. Geoinformação na gestão dos recursos hídricos em sub-bacia hidrográfica. Irriga. Botucatu. v. 1, p. 93-103, 2011.

VALENTE, R. O. A. Definição de áreas prioritárias para conservação e preservação florestal por meio da abordagem multicriterial em ambiente SIG. 2005. $121 \mathrm{f}$. Tese (Doutorado em Recursos Florestais)-Escola Superior de Agricultura "Luiz de Queiroz", Universidade de São Paulo, Piracicaba.

VETTORAZZI, C. A. Avaliação multicritérios, em ambiente SIG, na definição de áreas prioritárias à restauração florestal visando à conservação de recursos hídricos. $2006.151 \mathrm{f}$. Tese (Livre Docência em Geoprocessamento) - Escola Superior de Agricultura "Luiz de Queiroz", Universidade de São Paulo, Piracicaba.

YAGER, R. R. On ordered weighted averaging aggregation operators in multicriteria decision-making. IEEE Transactions on Systems Man and Cybernetics. New York. v. 8, n. 1 , p. $183-190,1988$.

ZHANG, X; YU, G.Q.; ZHAN, B.L.; PENG, L. Experimental Study on Slope Runoff, Erosion and Sediment under Different Vegetation Types. Water resources managenment. Berlin. v. 28, n. 9, p.2415-2433. 2014. 